\title{
Underground Measurements of Seismic Vibrations at the SSC Site
}

\author{
V.D.Shiltsev*1, V.V.Parkhomchuk*l and H.J.Weaver
}

\begin{abstract}
The results of underground measurements of seismic vibrations at the tunnel depth of the Superconducting Super Collider (SSC) site are presented. Spectral analysis of the data obtained in the frequency band from $0.05 \mathrm{~Hz}$ to $1500 \mathrm{~Hz}$ is performed. It is found that amplitudes of ambient ground motion are less than requirements for the Collider, but cultural vibrations are unacceptably large and will cause fast growth of transverse emittance of the SSC beams.
\end{abstract}

\section{0 Introduction}

Vibrations of the magnetic elements of the Superconducting Super Collider (SSC) are considered as one of the main sources of transverse emittance growth of the SSC beams. The SSC collider may be the first accelerator where ground motion can seriously jeopardize useful operation of the machine. The issue is that tolerable levels of vibrations for the SSC are at least a few orders of magnitude tighter than those for the largest existing hadron accelerators such as the Tevatron and SPS (CERN), because the transverse emittance of the SSC beam will be about 100 times smaller and the circumference will be about 10 times larger at the SSC than for those smaller machines. The last argument is valuable because a larger circumference means lower revolution and betatron frequencies, and it is dangerous because of the rapid increase of vibrations at lower frequencies. Also, the number of magnetic elements in the rings, which can disturb the ideal motion of the beams, is very large (thousands).

Vibration effects on collider performance have been studied in several works, $1-4,7$ and it was found that depending on the frequency of the noise, one can distinguish two mechanisms of beam perturbation. At low frequencies (much less than the revolution frequency), the noise produces a distortion of the closed orbit of the beam. Highfrequency noises-especially at frequencies near a fractional part of the betatron oscillation frequency $(600-1100 \mathrm{~Hz})$ at the SSC-cause direct transverse emittance growth. The following figures will give an idea of the seriousness of the issue:

1. The acceptable level of uncorrelated low-frequency motion of a single SSC quadrupole is about $0.1-0.3 \mu \mathrm{m} ; 3,1,2,7$

1* Guest scientist from Budker Institute of Nuclear Physics, Novosibirsk, Russia 


\section{DISCLAIMER}

Portions of this document may be illegible in electronic image products. Images are produced from the best available original document. 
2. High-frequency turn-to-turn jitter of every quad with an amplitude of approximately $10^{-4} \mu \mathrm{m}$ will cause emittance doubling after only $20 \mathrm{~h} .3,4,5,6$

(Damping time due to synchrotron radiation in the SSC is about $24 \mathrm{~h}$.)

Therefore, it is necessary to measure ground vibrations over an extremely large frequency range from fractions of a hertz (or the lowest possible frequency) to a few kilohertz. Experimental investigation of underground vibrations at the SSC site at frequencies of 1-100 Hz was made by The Earth Technology Corporation of Long Beach, $\mathrm{CA}$, in $1989 .{ }^{8}$ Very detailed analysis was done, but the most interesting frequencies in the kilohertz range and the most powerful vibrations at frequencies below $1 \mathrm{~Hz}$ were not investigated. The Vibrational Workshop held at the SSC Laboratory in February 1992 also emphasized the lack of information about these important regions. 9 In our previous papers 10,11 we reported results of measurements of ground motion and the SSC dipole vibrations made at the Accelerator Systems String Test (ASST) which is placed on the surface of the ground. High-precision seismic equipment from Budker INP (Novosibirsk, Russia) allowed us to obtain useful data up to frequencies 20 times larger and 20 times lower than those previously investigated - it covered frequency band of $0.05-2000 \mathrm{~Hz}$. The analysis had shown some amplifications of ground vibrations due to resonant properties of magnetic elements and their support.

This paper is devoted to underground seismic measurements at the SSC site in the frequency band of $0.05-1500 \mathrm{~Hz}$. In Section 2.0 we describe equipment, hardware, data processing, and conditions under which measurements were made. Principal results of measurements, the discussion, and comparison with other data are presented in Section 3.0. Further experiments, development, plans, and main conclusions are summarized in Section 4.0 .

\section{0 Experimental}

All results presented in this paper were obtained in the Exploratory Shaft (ES) placed in the injector site of the SSC during a 10 week period (June 23 - September 1st, 1993). The shaft (see Fig. 1 from Ref. 12) is $16.5 \mathrm{ft}$ diameter from the surface down to the $195 \mathrm{ft}$, then $10 \mathrm{ft}$ in diameter to the full depth (265 ft), and it penetrates Austin chalk and Eagle Ford shale. The shaft drilling was performed at November 1991 and the horizontal adit was drilled in December 1991 . The shale is potentially a more difficult medium and personnel of the joint venture of Parsons Brinkerhoff and Morrison Knudsen (PB/MK) studied the rock reaction to excavation. The horizontal adit $-8 \mathrm{ft}$ wide, $14 \mathrm{ft}$ high and 45 $\mathrm{ft}$ long, directed South - is $215 \mathrm{ft}$ (about $68 \mathrm{~m}$ ) below the surface at the interface of two formations. Equipment and personnel were lowered in a steel cage. One SM-3KV type geophone was installed in the end of the adit. The same type of probe was also installed on the surface not far from the shaft (see Fig. 1). These two probes were used to measure ground vibrations in the adit and on the surface and to observe the correlation between the motion of two points situated down and up the shaft (we refer these as 'down' and 'top'). During the period of observations the SSC injector complex was under construction and operation of heavy machinery, excavation works, industrial car traffic occured in Low Energy Booster and Linac sites within about $1 \mathrm{~km}$ distance from the ES. The effect of this was especially seen at weekdays (see Section 3.0). 
Two SM-3KV probes No.1112 and No.1140 were carried from the Budker INP (Novosibirsk, Russia) in accordance with inter-laboratory agreement 92-W-11138, Attachment 26 , and had been previously tested in vibrational studies for linear collider VLEPP ${ }^{15}$, Novosibirsk B-Factory VEPP-5 16 as well as in ASST measurements 10,11.

A commercial velocitymeter SM-3KV was modified to extend the frequency band to $0.05-1500 \mathrm{~Hz}$. The proper pendulum period of the probe is $2 \mathrm{~s}$. A special electrical feedback system modifies the raw signal from the coil of the pendulum, which vibrates in the magnetic field system; thus, the output signal is proportional to the velocity of vibrations without resonance, emphasizing the proper period. At frequencies above 200 $\mathrm{Hz}$ the feedback system gain is small and it doesn't improve probe characteristics. The probe allows us to measure vertical as well as horizontal vibrations after some simple mechanical transformations. During the investigations two probes in the vertical variant were used, with both calibrated in the working frequency range. Calibration at frequencies above $100 \mathrm{~Hz}$ was done through the special calibrated coil installed in the probes and by using a special vibrating table in Novosibirsk (Ref. 18) and good confirmation of undirect calibration was found. Results of the calibration are presented in Figure 2. The difference in the sensitivities of the two probes is less than $10 \%$. The mass of the probe is about $6 \mathrm{~kg}$, and its size is $15 \mathrm{~cm} \times 15 \mathrm{~cm} \times 25 \mathrm{~cm}$. Signal-to-noise ratio for SM-3KV probe with the smallest observed ground vibration signals is shown in Figure 3. One can see that the signal-to-noise ratio is less than 2 above $1000 \mathrm{~Hz}$ and below $0.05 \mathrm{~Hz}$. Under usual and noisy conditions these ratio becomes many times more (see Section 3.0 below).

In investigations of sound waves descried below we used calibrated piezocelectric hammer made by Dytran Corporation. Electrical signal from the hammer is proportional to the force of strike - it has sensitivity of $1 \mathrm{mV} / \mathrm{lb}$. The hammer has a mass about $2.5 \mathrm{~kg}(5$ lbs wt).

All electrical signals from probes were digitized and developed by a CAMACbased experimental set-up named ASSA, which includes:

- CAMAC crate

- CAMAC crate controller

- Two 10-bit, 4-channel CAMAC ADC ZIIS-4 type

- CAMAC differential amplifiers for all kinds of probes (this allows us to change the total gain from 0.1 to $10^{5}$ and low-pass frequency filters from $1 \mathrm{~Hz}$ to $10000 \mathrm{~Hz}$ )

- Two 256-K, 24-bit word CAMAC memories

- CAMAC timer

- Interface CAMAC (IBM PC)

- IBM 386 personal computer.

The ASSA set-up is fully autonomous and needs only a $110-\mathrm{V}$ outlet.

Signals from all probes were digitized simultaneously by ADCs with a sampling frequency (changeable by timer from $0.1 \mathrm{~Hz}$ to $32 \mathrm{kHz}$ ) and then were sent to memory for storage. The maximum memory available for one channel is $64-\mathrm{K} 24-\mathrm{bit}$ words. It corresponds to $17.8 \mathrm{~h}$ of permanent measurement time with a sampling rate of $1 \mathrm{~Hz}$ or 
about $1 \mathrm{~min}$ with $1 \mathrm{kHz}$. For long measurements we used low-pass filters at $2 \mathrm{~Hz}$ or 20 $\mathrm{Hz}$; for fast analyses $2000-\mathrm{Hz}$ and $10000-\mathrm{Hz}$ filters were applied.

The software used allows us to analyze data in both the time and the frequency domain, to transform raw signal data to vibration amplitudes (i.e., transform volts to micrometers), to change all variable parameters of hardware (sampling frequency, gains, filters), to calculate power spectral densities of all signals and spectra of correlation between all pair of channels, and to present results graphically and produce hard copy on a printer.

For calculations of spectra we used the optimized 512-point Raider-Brenner algorithm based on a 16-point Winograd algorithm for discrete Fourier transformation. (See Reference 13 for an example.) On an IBM PC/386, the algorithm works twice as fast as the usual Fast Fourier Transformation (FFT) technique of Cooley and Tukey. This algorithm is very useful because in order to reduce statistical errors we can average over a greater number of spectra (usually 63). Two types of data filtration were used when necessary: Hanning filter (see Reference 14 for an example), and Antimed filter (see Ref. 11 for detailed description), which provides more true data under some conditions.

The power spectral density (PSD) $S(f)$ which we calculated have the following relation to rms value of signal $X_{m s}\left(f_{1}, f_{2}\right)$ in frequency band from $f_{1}$ to $f_{2}$ :

$$
X_{\text {ms }}\left(f_{1}, f_{2}\right)=\int_{f_{1}}^{f_{2}} S(f) d f
$$

The spectrum of correlation $K(f)$ of two signals $X(t)$ and $Y(t)$ (or, mutual correlation spectrum) that we use in this paper is defined as:

$$
K(f)=\frac{\left.<X(f) Y^{*}(f)\right\rangle}{\left[\left\langle|X(f)|^{2}\right\rangle\left\langle|Y(f)|^{2}\right\rangle\right]^{1 / 2}}
$$

Here the brackets $<\ldots .>$ mean averaging over the 63 measurements, and $X(f)$ is the Fourier transformation of $X(t)$.

The main aims of our investigations were to determine quantitative characteristics of the SSC site ground vibration at the tunnel depth and compare it with surface data.

\subsection{Results}

As we mentioned above, daytime amplitudes of ground motion were usually larger than at night and weekends due to construction work at Injector site. Fig. 4 demonstrates raw time records of signals from 'top' and 'down' probes afternoon (Fig.4 a), b)) and at night (Fig. 4 c),d)). One should mention that the scale of $\mathrm{Y}$-axis for night data is 40 times less than on the corresponding daily plots. During the day heavy machinery produced about $1200 \mathrm{mV}$ signal at 'top' and about $600 \mathrm{mV}$ at 'down' probes with frequency about 30 $\mathrm{Hz}$. That correspond to about 0.08 micron and 0.04 micron amplitudes (see calibration in Fig. 2). At night vibrations at frequencies of tens $\mathrm{Hz}$ and higher are about hundred times less and one can clearly see low-frequency ground motion. This motion, with amplitude of about 0.1 micron and period 5-7 sec, is due to micro seismic waves produced by the 
closest ocean (Gulf of Mexico). Both 'top' and 'down' seismic-probes show practically the same low-frequency signals, while high-frequency noise is about 4 times larger on the surface.

The probability that amplitude of the ground vibrations is more than a given value of $X$ (micron) during any 5-sec time interval (this is natural scale of micro seismic wave period) is presented in Fig. 5. Data obtained during 1 July - 13 July are developed for this picture. Here solid line and marked points correspond to 'down' and 'top' data. Dash line represents the fit :

$$
d W(x>X)=\frac{0.004}{X(\mu m)^{-1.5}}
$$

One can see, that the probability that ground motion is less than $0.1-0.2$ micron is about $100 \%$. Large amplitudes $0.2<x<1$ micron are seen more often on the surface. More significant events correspond to remote and small local earthquakes (the SSC site statistics says that local earthquakes are usually small and very rare, see, for example Ref. 20). About twice a week we observed the ground waves from TXI quarry blasts (2000-5000 $\mathrm{lb}$. of explosive material) with amplitude up to 1.5 micron and period about $1-2 \mathrm{~s}$. The quarry is situated about 10 miles North-West of the ES, not far from Midlothian, TX. An example of such blast waves is shown in Fig. 6 . The ground vibrations in the shaft and on the surface are the same during about $8 \mathrm{~s}$ of the event.

Fig. 7 presents about monthly statistics of events with large amplitudes ( 30 July -til 24 August). There is shown that the mean time $T$ between events with amplitudes more than $X$ grows approximately linearly with $X$ (see fit in Fig.7) :

$$
T(\text { days })=2.3 * X \text { (micron) }
$$

This is reflection of well known "Gutenberg-Richter law" on frequency of earthquakes (see, for example Ref. 21). Most of events with amplitudes 1-5 micron produce the same signals in the shaft and on the surface. Nevertheless during M6.0 Queen Charlotte Island earthquake at 2:40 a.m. (Texas time) 3rd of August, 1993 we observed that 'down' probe signal had an amplitude about 15 micron while only 10 micron motion was on the surface. The duration of that earthquake in Texas was about $40 \mathrm{~min}$. and waves had a period 5-10 s.

Measurements of propagation of waves from surface to down shaft were made with use of calibrated hammer. Simultaneously measured signals from the hammer and the two probes are shown in Fig. 8 a), b) and c) correspondingly. Experimentator hit the ground by hammer about $5 \mathrm{~m}$ away from 'top' probe which shows extremely high level of signal (about 10-20 times more than down shaft where amplitude about 0.002 micron was detected). After calculations of time delay between SM-3KV probes signals $(22 \mathrm{~ms})$ we found that sound velocity (P-wave) is about $3000 \mathrm{~m} / \mathrm{s}$. The velocity of sound in upper soil was found about $1.5-2.0 \mathrm{~km} / \mathrm{s}$. Fig. 9 demonstrates how peak amplitude of 'top' probe 
signal decreased while distance $L$ between that probe and the point of hammer strike increased up to $90 \mathrm{~m}$. Dashed line in Fig. 9 is plotted accordingly to geometrical factor $1 / L$ for spherical wave which propagates without dissipation of energy.

Fig. 10 presents power spectral density of ground vibrations on the surface and in the shaft under "typical noisy" and "typical quiet" conditions (about noon and midnight of August 7,1993 ). Each PSD consists of three spectra with different ADC's sampling frequencies $(20 \mathrm{~Hz}, 200 \mathrm{~Hz}$ and $2000 \mathrm{~Hz})$ and with corresponding low-pass analog filters. In Fig. 10 a) one can see, that day-time technical noises do not influence on vibrations at the shaft only below $0.5 \mathrm{~Hz}$ where curves 1 and 2 join each other. Small peak around 0.2 $\mathrm{Hz}$ is due to micro seismic waves described above. At frequencies $1 \mathrm{~Hz}$ and higher the power of vibrations increases $10^{3}-10^{5}$ times due to technical activity. Without taking into account peaks, the PSD may be roughly approximated by formula :

$$
S(f)=\frac{A}{f^{-3}}
$$

where constant $A=0.7 \mu \mathrm{m}^{2} / \mathrm{Hz}$ under the noisy conditions and $A=2 * 10^{-4} \mathrm{\mu m}^{2} / \mathrm{Hz}$ in the quiet case. Vibrations of ground surface are about 4 times more powerful and even at low frequencies (below $1 \mathrm{~Hz}$ ) the technical activity significantly increases vibrations.

Fig. $11 \mathrm{a}), \mathrm{b})$, c) show how rms values of ground vibrations in frequency bands $0.08 \mathrm{~Hz}-0.2 \mathrm{~Hz}, 10 \mathrm{~Hz}-20 \mathrm{~Hz}$ and $500-1000 \mathrm{~Hz}$ correspondingly varied in time during two weeks in July 1993 (see Eq. (1) for reference on rms value). Accordingly to Fig. 11 a) amplitudes of micro seismic waves are the same for the two probes, slightly varies in time and have the value about 0.1-0.2 micron (during our spring measurements in the ASST that amplitude varied from 0.1 micron to about 1 micron, see Ref. 10,11). Sharp peaks in Fig. 11 a) are connected with local and remote earthquakes and events.

In contrast, high frequency vibrations (see, Fig. 11 b) and c)) strongly depends on time and clearly show quiet time at weekends, drop of vibrations at lunch time (every weekday) and even reflect the fact that there are more activity at the beginning of the week than at Fridays. As we said in the Introduction, the level of ground motion vibrations at frequencies of several hundreds $\mathrm{Hz}$ (upto $1 \mathrm{kHz}$ ) acceptable for the SSC collider is about 0.0001 micron. Fig. $11 \mathrm{c}$ ) shows that this level is overcame 3-10 times at weekdays, especially on the surface of the ground. It will cause fast growth of transverse emittance of the SSC beams. On-line simulations of emittance growth (described in Ref. 6) predicted increment of the emittance about 50 times over the designed value. There were also demonstrated that the feedback system can strongly damp this effect.

Fig.12 presents real part, imaginary part and modulus of correlation spectrum $K(f)$ between vibrations on the surface and in the adit under quiet conditions (see a), b) and c) correspondingly). Modulus of correlation spectra (or coherence spectra) in noisy conditions is shown in Fig. $11 \mathrm{~d}$ ). One can see, that inspite of some increasing of correlation at frequencies above $10 \mathrm{~Hz}$ at noisy case, a good correlation (higher than 0.7 ) exists only for waves with frequencies $0.1-0.5 \mathrm{~Hz}$ and $1-5 \mathrm{~Hz}$. Decreasing of correlation below $0.1 \mathrm{~Hz}$ may be due to several effects : noises of seismic probes electronics, different response of the tunnel and the surface on fluctuations of atmospheric pressure, and due to significant uncorrelated slow ground motion (see, for example, Ref. 7). It is 
hard to give correct explanation of the effect with equipment we used. We plan to make another measurements with special low frequency seismoprobes to investigate slow ground motion.

\section{0 Discussion of Results and Conclusions}

Comparison of the spectra of ground motion measured in the SSC Exploratory Shaft with other worldwide data is presented in Fig. 13 a). PSD of ground vibrations at the tunnel depth of the SSC, the UNK tunnel (Protvino, Ref. 15), CERN (TT2A tunnel, Ref. 22) and at the KEK (Tsukuba Mt. shaft, Ref. 23). All spectra were obtained under quiet conditions and have rather similar values. Fig. $13 \mathrm{~b}$ ) shows comparison of our data (curves 1 and 2) with previous measurements at the depth of $19 \mathrm{~m}$ in the SSC site (see Ref.8). Dash line in Fig. 13 b) represents level of acceptability for ground motion (taken from Ref. 10,11$)$ : at low frequencies it determines as condition for beam-beam separation in the interaction point of the SSC less than $10 \%$ of beam size in the assumption of uncorrelated motion of magnetic elements. We have to mention that at micro seismic peak frequencies $0.1-0.3 \mathrm{~Hz}$ those motions are well correlated, but the issue of uncorrelated displacements with frequencies less than $0.1 \mathrm{~Hz}$ are still not carefully investigated experimentally. At high frequencies of about $500-1500 \mathrm{~Hz}$ the dashed line shows level of qudrupoles jitter which will cause doubling of transverse emittance of the beams during 20 hours of operation of the SSC. One can see that biggest observed vibrations are far above this level.

While slow vibrations with big amplitudes are interesting from the point of view of distortion of the closed orbit, we have in future plan to continue measurement of spectral and correlation properties of ground vibration with new low-frequency seismoprobes SDE type ${ }^{18}$. (Those seismometers work in the band $0.001 \mathrm{~Hz}-1 \mathrm{~Hz}$.) This will give necessary information for design of dynamical adjustment scheme which provide head-on beam-beam collisions ("Jostlein scheme"19, for example).

We found, and on-line simulations ${ }^{6}$ of transverse emittance growth confirmed it, that technical activity (as it was during our underground measurements) will cause unacceptably large increment of the beams' emittances. In Ref. 10 and 11 we found that mechanical resonances of magnetic elements and their supports can increase several times this effect. Moreover, considered in Ref. 5 the phenomena of fluctuation of the dipole field due to variation of vacuum chamber shape caused by the turbulence of the liquid Helium flow may add concern on emittance preservation issue (this effect surely needs careful experimental investigation and we have it in plans also). As it was mentioned in Ref. 6 there are only three way to avoid this effect : to reduce vibrations; to increase fractional part of the tune and to install transverse feedback system. The last choice contains more freedom for the SSC than two another.

On our mind it is necessary to include in the design of the SSC a subsystem for monitoring of seismic vibrations. Such a system may consist of 10-12 small seismic stations, similar to which we used in these measurements, which will set around the Collider tunnel and may be one central station with extended equipment for ultra slow ground motion. 


\section{Acknowledgments}

The authors acknowledge discussions and suggestions from George Bourianoff, Alex Chao, Rae Stiening, Mike Syphers, Gennady Stupakov, Richard Talman, Alex Harvey and other participants of the SSC Interaction Regions weekly meetings. We are thankful to Valery Lebedev (Budker INP), William Nexsen, Edward Tsyganov, Anatoly Medvedko, Sol Shapiro, Jack Peterson (LBL) and David Johnson for their permanent interest in these experiments. We deeply appreciate help of Bob Webber, Victor Brouk, Jean Greenwell, Duane Plant and Rickey Broulette (PB/MK) in organization of these measurements. An independent calibration of SM-3KV probes in Budker INP made by Boris Baklakov and Pavel Lebedev was very useful for us and we thank them for it and their participation in preparation of equipment for the work. A lot of work on design, construction and development of electronics for seismic measurements were done by Alexander Sleptsov, Anatoly Putmakov, Andrey Chupiro and Shavkat Signatullin (Budker INP).

Authors are grateful to A.N. Skrinsky (Budker INP), N.S Dikansky (Budker INP) and Rainer Meinke for their support of our experiments in the SSC Laboratory.

\section{REFERENCES}

1.G. E. Fischer and P. Morton, "Ground Motion Tolerances for the SSC," SSC-55, 1986. 2.K. Y. Ng and J. O. Petersen, "Ground Motion Effects on the SSC," SSC-212, 1989.

3.V. A. Lebedev, V. V. Parkhomchuk, V. D. Shiltsev, and A. N. Skrinsky, "Suppression of Emittance Growth Caused by Mechanical Vibrations of Magnetic Elements in Presence of Beam-Beam Effects in the SSC," Preprint INP 91-120, Novosibirsk, 1991.

4. V. A. Lebedev, V. V. Parkhomchuk, V. D. Shiltsev, and G. V. Stupakov, 'Emittance Growth Due to Noise and Its Suppression with the Feedback System in Large Hadron Colliders," SSCL-Preprint-188, 1993.

5. V.V.Parkhomchuk and V.D.Shiltsev, "Is Transverse Feedback Necessary for the SSC Emittance Preservation? (Vibration Noise Analysis and Feedback Parameters Optimization)", SSCL-622, June 1993.

6. V.D.Shiltsev and V.V.Parkhomchuk, "Real-Time Modeling of Transverse Emittance Growth Due to Ground Motion", SSCL-639, September 1993.

7. V.Parkhomchuk, V.Shiltsev and G.Stupakov, "Slow Ground Motion and Operation of Large Colliders", SSCL-Preprint-470, July 1993.

8. The Earth Technology Corporation (Long Beach, CA), 'Field Measurements and Analyses of Underground Vibrations at the SSC Site," Report No. SSC-SR-1043, Dec. 1989.

9. "Summary and Presentations of the Workshop on Vibrational Control and Dynamic Alignment Issues at the SSC," ed. H. J. Weaver, SSCL-SR-1185, Feb. 1992.

10. V.V.Parkhomchuk, V.D.Shiltsev and H.J.Weaver, "Measurements of Ground Motion Vibrations at the SSC", SSCL-Preprint -323, May 1993 and Proc. of 1993 IEEE Part. Acc. Conf., Washington DC, May 1993. 
11. V.V.Parkhomchuk, V.D.Shiltsev and H.J.Weaver, "Measurements of Ground Motion and SSC Dipole Vibrations", SSCL-624, June 1993.

12. "SSC Breaks Ground with Test Shaft", Civil Engineering, October 1991, p. 20.

13. R. E. Bleihut, Fast Algorithms of Data Processing, Addison-Wesley, 1985.

14.R. W. Hamming, Digital Filters, Prentice-Hall, Englewood Cliffs, N.J., 1977.

15.B.A.Baklakov, P.K.Lebedev, V.V.Parkhomchuk, A.A.Sery, V.D.Shiltsev, and A.I.Sleptsov, 'Investigation of Seismic Vibrations and Relative Displacement of Linear Collider VLEPP Elements," Proc. of 1991 IEEE Part. Accel. Conf., San Francisco, p. 3273, May 1991.

16. V.A. Lebedev, P. K. Lebedev, V. V. Parkhomchuk, and V. D. Shiltsev, "Transverse Vibration of Electron Beam and Ground Motion Measurements at VEPP-3 Storage Ring," Preprint INP 92-39, Novosibirsk, 1992.

17. H. K. Given, "Variations in Broadband Seismic Noise at IRIS/IDA Stations in the USSR with the Implementations for Event Detection," Bulletin of the Seismological Society of America, Vol. 80, No. 6, p. 2072, Dec. 1990.

18. B. A. Baklakov and P. K. Lebedev, private communication.

19. H. Jostlein, "Automatic Beam Centering at the SSC Interaction Regions," Fermilab TM-1253, March 1984.

20. J.E.Keller et. al, "Minimum recommended SSC Laboratory Seismic Design requirements", SSCL-Note-823, June 1993.

21. "Fractals and Chaos in Geology and Geophysics", D.L.Turcotte, Cambridge University Press, 1992, p.36.

22. V.Balakin, et. al, "Measurements of Seismic Vibrations in CERN TT2A Tunnel for Linear Collider Studies", CLIC-Note-191, 1993.

23. Y.Ogava, et. al, "Vibration Issues Regarding Linac Beam Characteristics", KEK Preprint 92-104 and Proc. of the 16th Int. LINAC Conf., Ottawa, Canada, Aug. 1992.

\section{FIGURE CAPTURES}

Fig.1 : View of the SSC Exploratory Shaft and underground experiments.

Fig.2 : Calibration curve of SM-3KV probes (No.1112 and No.1140).

Fig. 3 : Signal-to-noise ratio under very quiet conditions.

Fig. 4 : a) Raw record of 'top' probe signal at 13:00, Fri., July 30.

b) Raw record of 'down' probe signal at 13:00, Fri., July 30.

c) Raw record of 'top' probe signal at 02:20, Mon., July 26.

a) Raw record of 'down' probe signal at 02:20, Mon., July 26.

Fig.5 : Function of probability to find a ground motion with amplitude more than $X$ during $5 \mathrm{~s}$ time interval vs. $X$ (solid line -for 'down' probe, points - for 'top' probe, dashed line - fit, see Eq. (3) in text).

Fig.6 : Waves from quarry blast 10 miles away (dashed line- 'down' probe, solid line - 'top' probe). 
Fig. 7 : August 1993 statistics of large amplitude events : mean time between events vs. its amplitudes (dashed line - fit, see Eq.(4) in text).

Fig. 8 : Raw data record of effect of hammer strike on the surfäce :

a) signal from calibrated hammer.

b) signal from probe on the surface.

c) signal from probe in the adit (68 $\mathrm{m}$ depth).

Fig. 9 : Peak amplitude of 'top' probe vs. distance to the hammer strike point.

Fig. 10: a) Power spectral density of ground vibrations at $68 \mathrm{~m}$ depth ( 1 - in a weekday conditions, 2 - at night).

b) Power spectral density of ground vibrations on the surface (1 - in a weekday conditions, 2 - at night).

Fig. 11: a) Rms value of ground vibrations in frequency band 0.08-0.2 Hz in July 1993 (top graph - on the surface, bottom - in the shaft).

b) Rms value of ground vibrations in frequency band 10-20 Hz in July 1993 (top graph - on the surface, bottom - in the shaft).

c) Rms value of ground vibrations in frequency band 500-1000 Hz in July 1993 (top graph - on the surface, bottom - in the shaft).

Fig. 12: a) Real part of correlation $K(f)$ between 'top' and 'down' ground vibrations.

b) Imaginary part of correlation $K(f)$ between 'top' and 'down' ground vibrations.

c) Coherence ( modulus of correlation $K(f)$ ) between 'top' and 'down' ground vibrations.

d) Coherence ( modulus of correlation $K(f)$ ) between 'top' and 'down' ground vibrations under noisy conditions.

Fig. 13: a) Comparison of power spectral density of ground vibrations in the SSC exploratory shaft under quiet conditions with other data (see comments in text).

b) Comparison of power spectral density of ground vibrations in the SSC exploratory shaft under noisy(1) and quiet(2) conditions with previous measurements (Ref.8) in the SSC site at depth $19.5 \mathrm{~m} \mathrm{(3)}$ and level of acceptability for ground vibrations from Ref. 10,11 (see comments in text). 



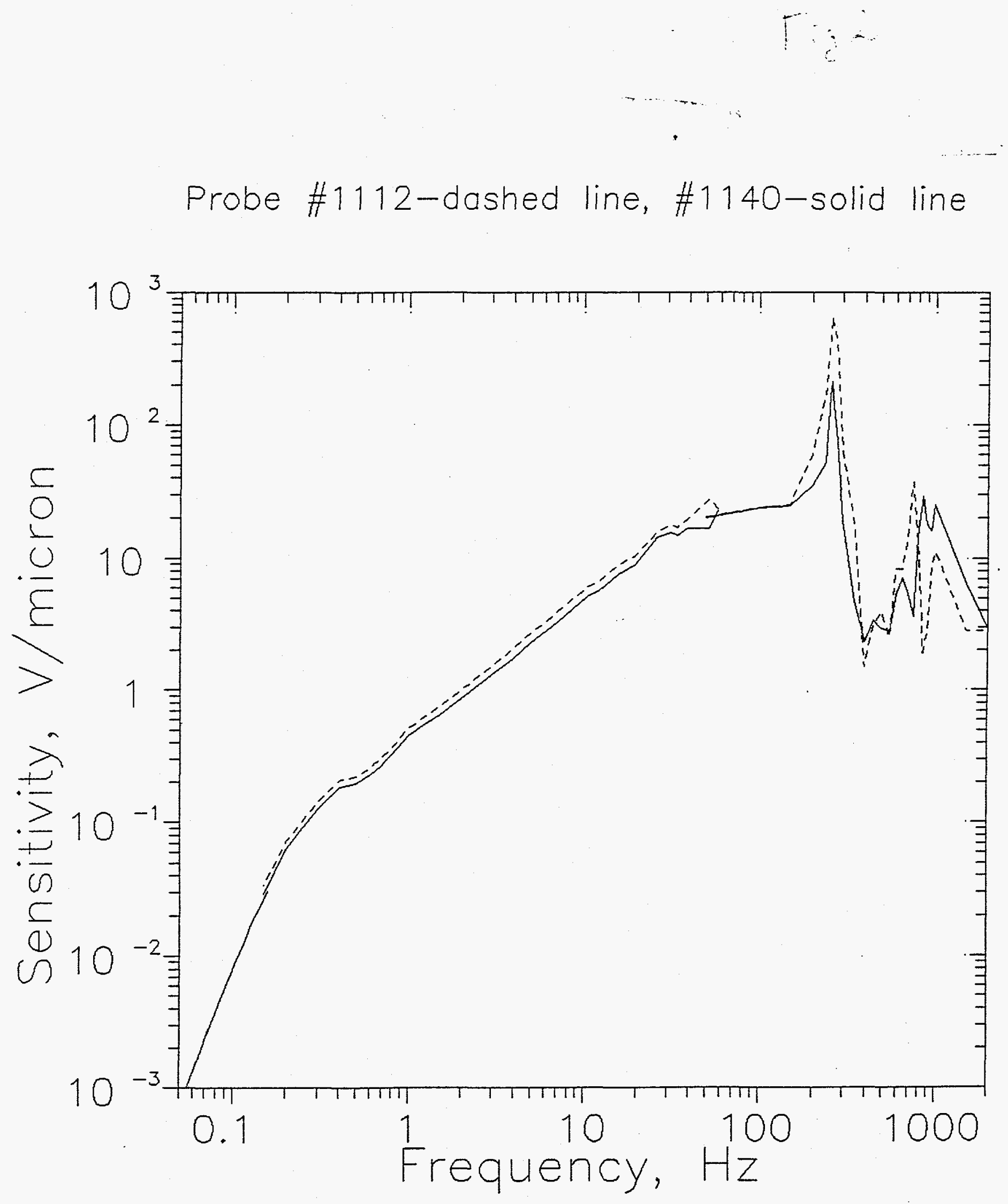


$F 8^{3}$

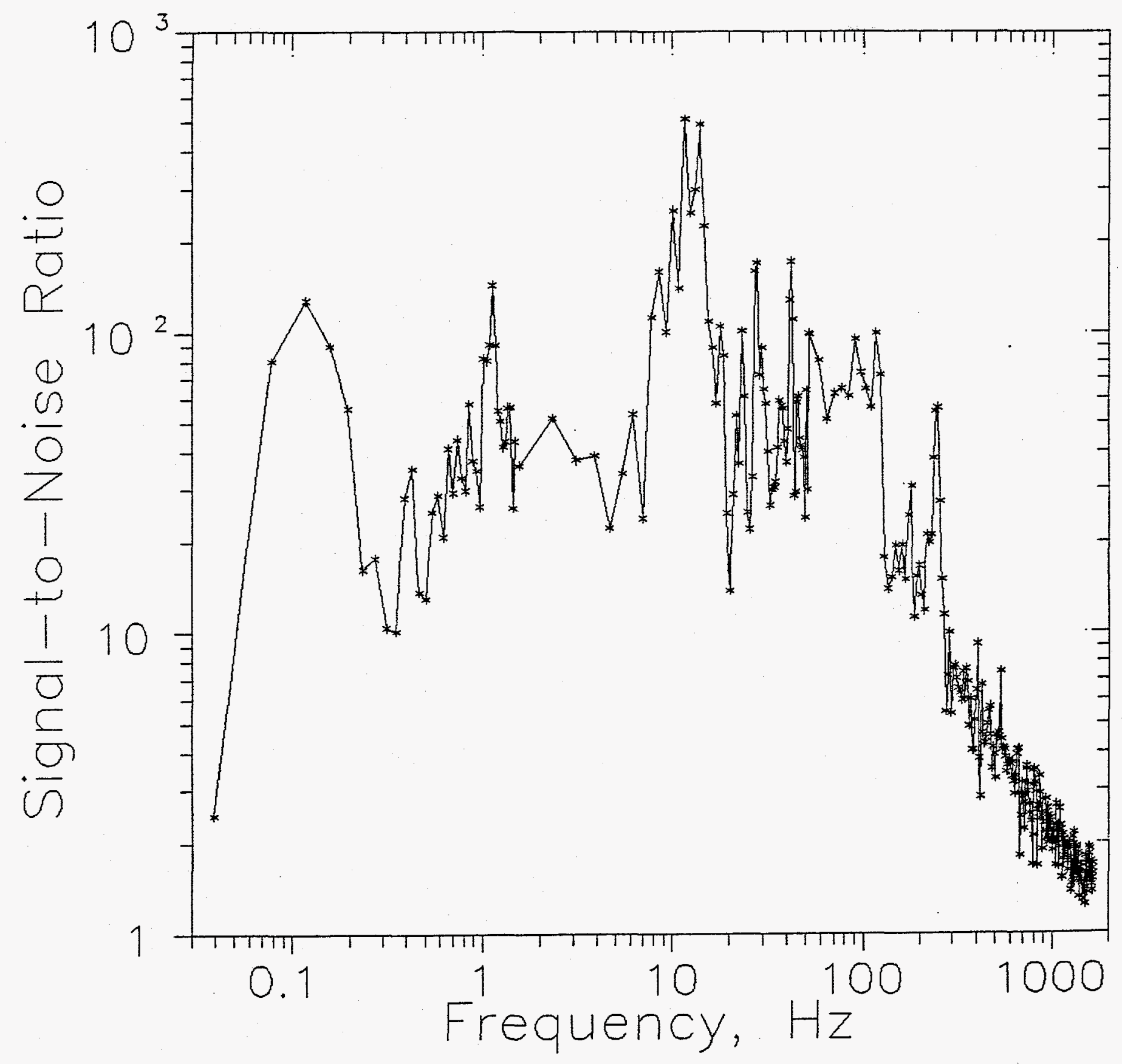



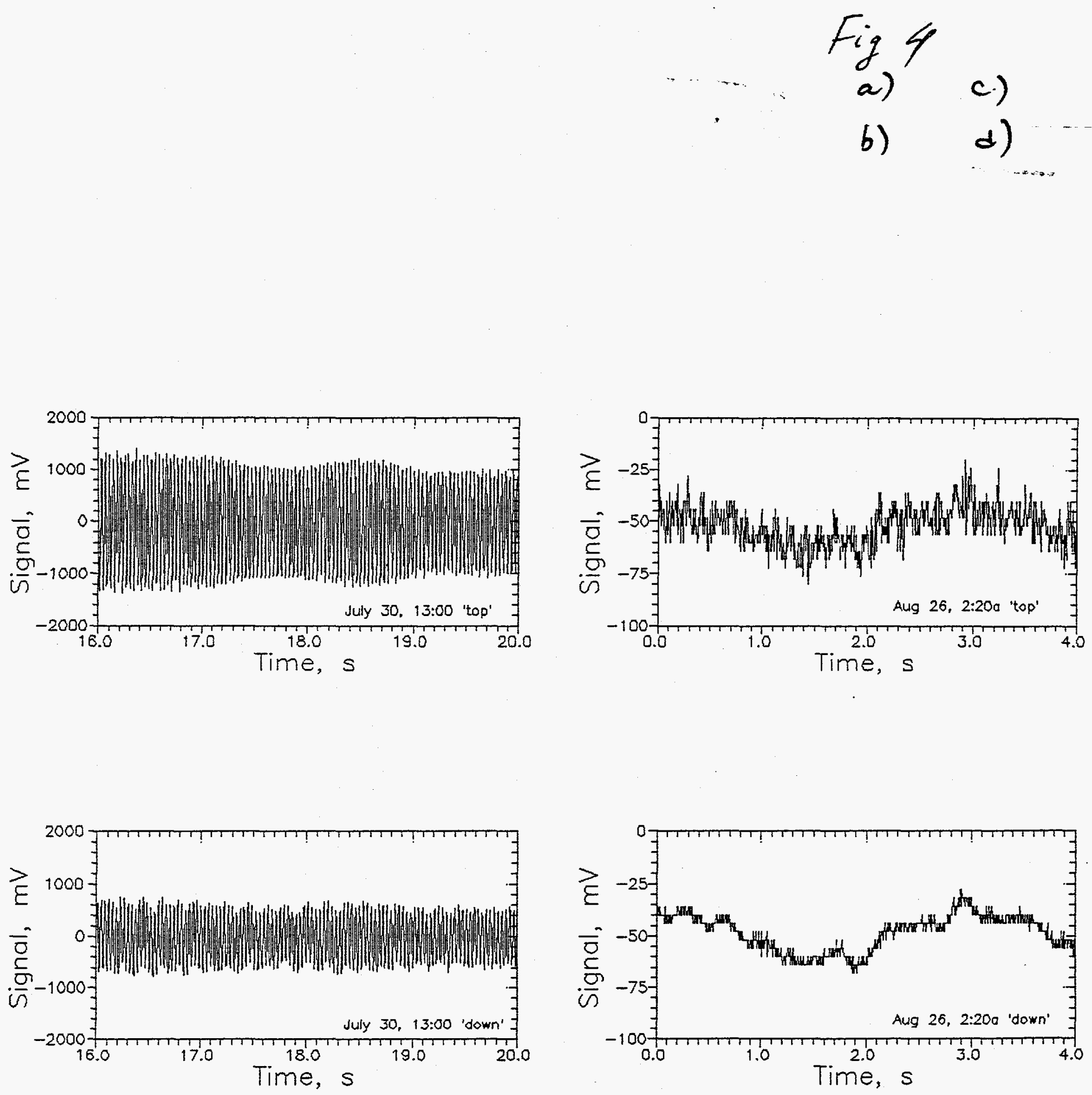
Fig 5

Seeking over 5 sec intervals Solid - down shaft

Points - top of the shaft

Dash - fit : $Y=0.004 *(X * *-1.5)$

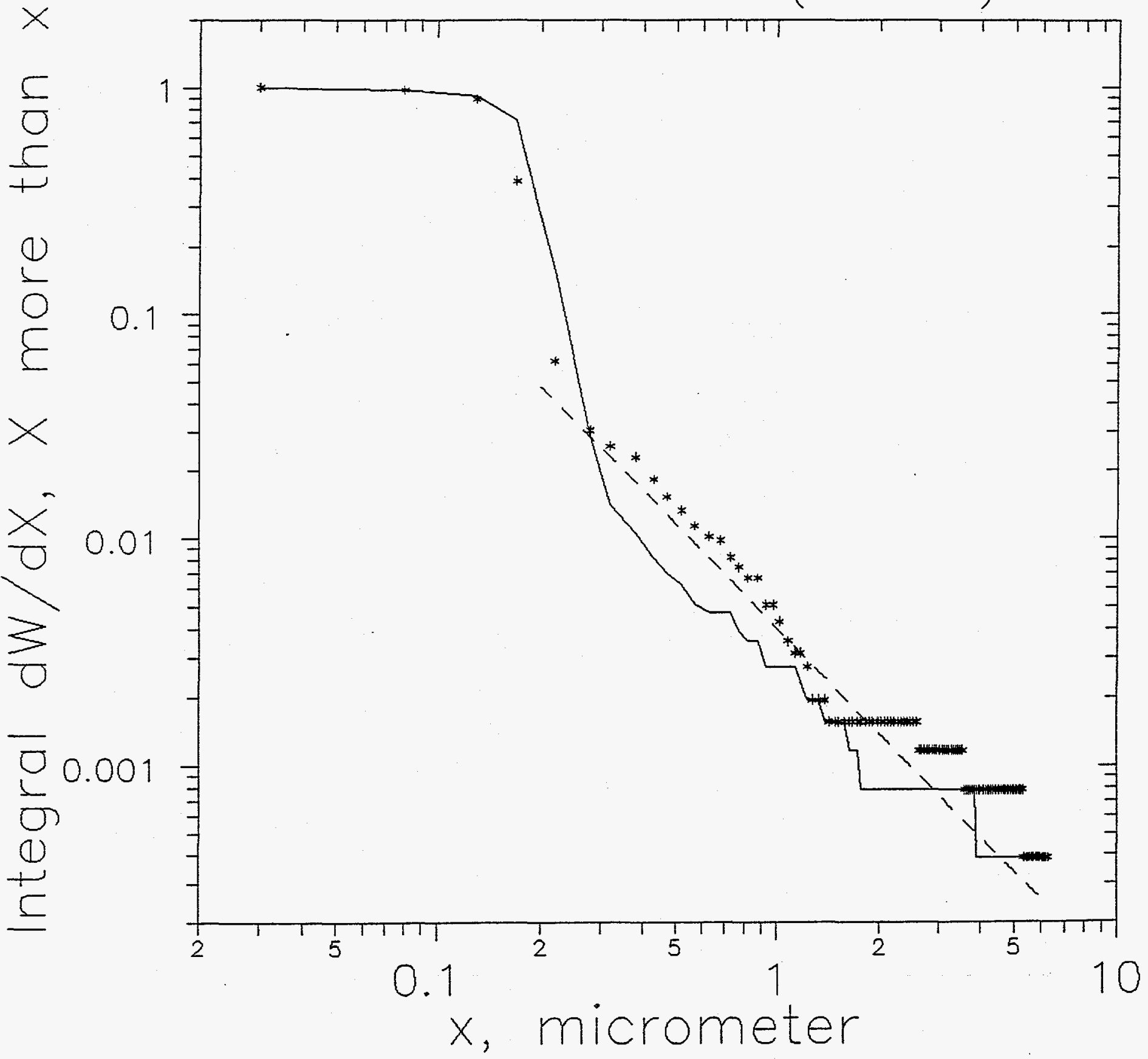


Fig 6

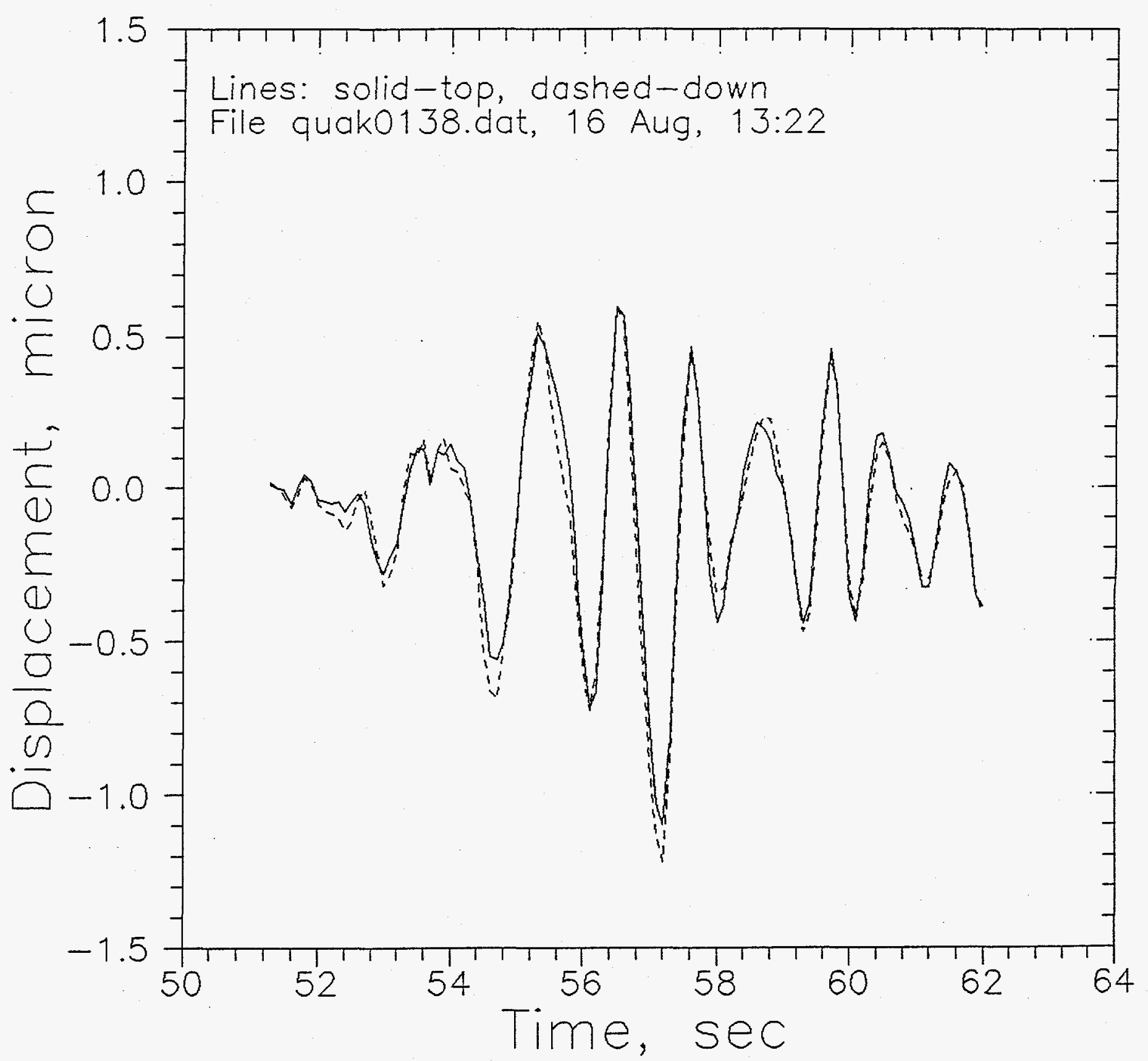


Fig 7

Mean time $T$ between events with amplitude more than $X$

Dash : fit $T=2.3$ (day) $* X$ (micron)

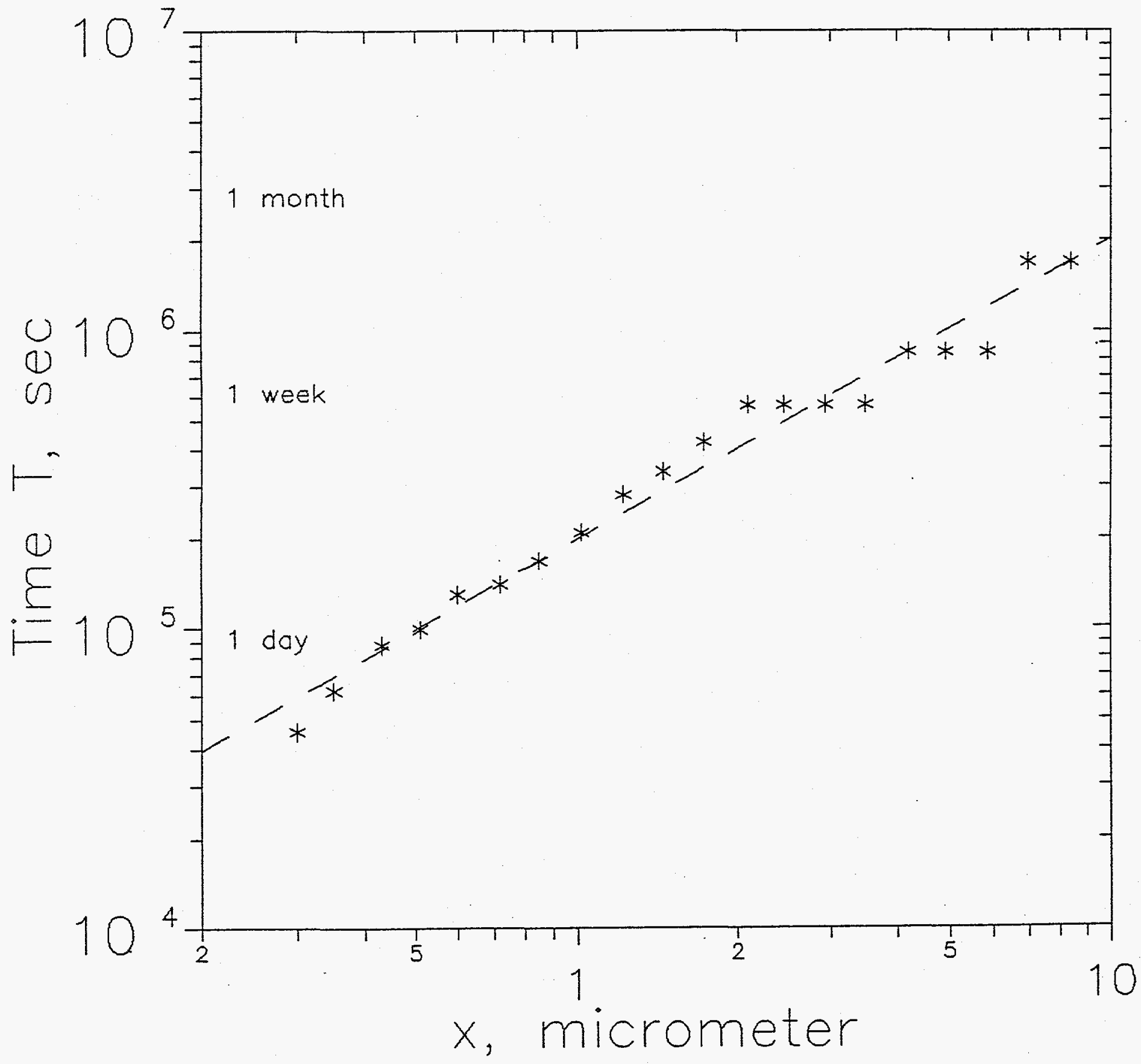



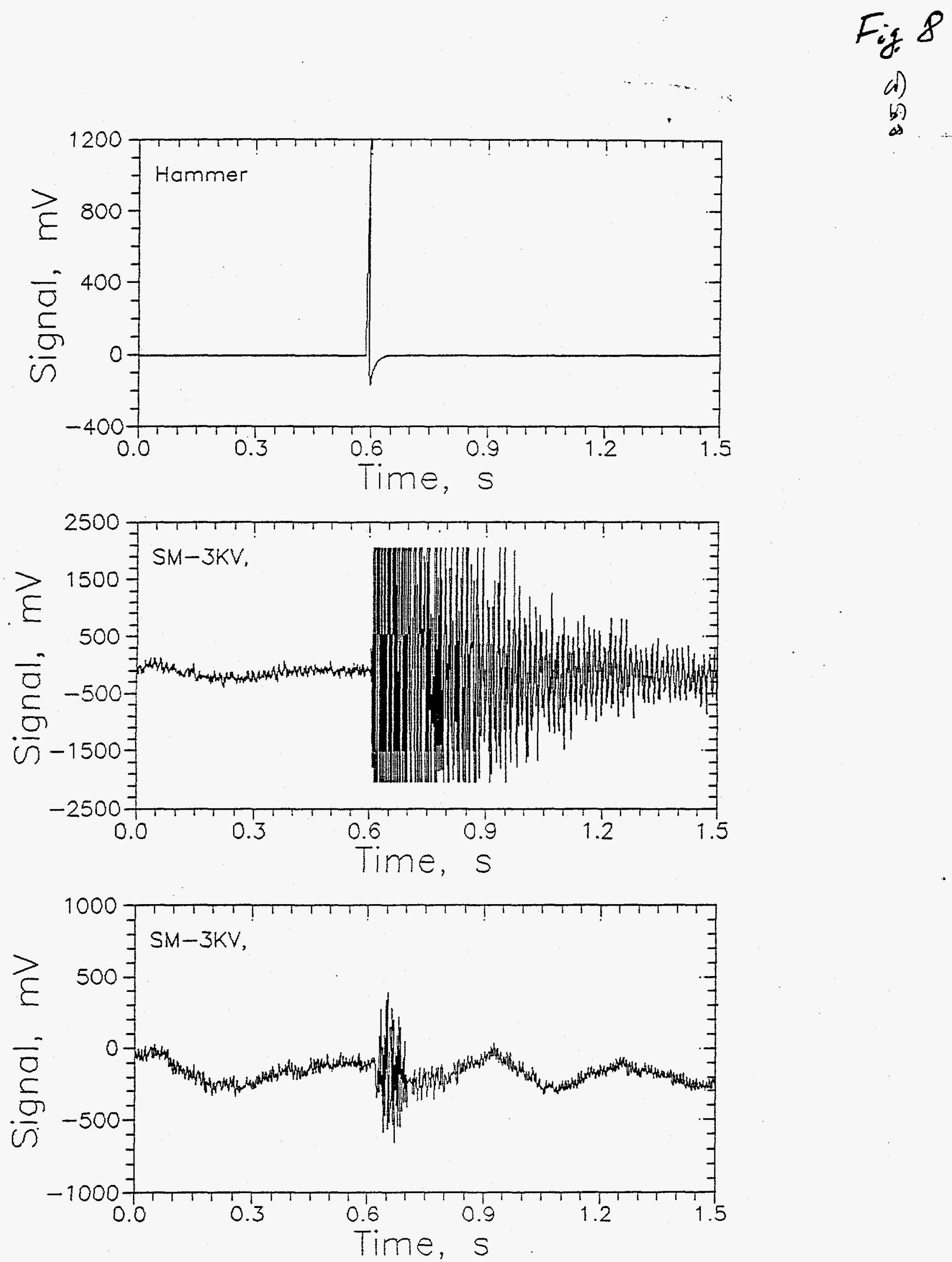
Fig 9

Dased line: fit $A=2 E+4 / L$

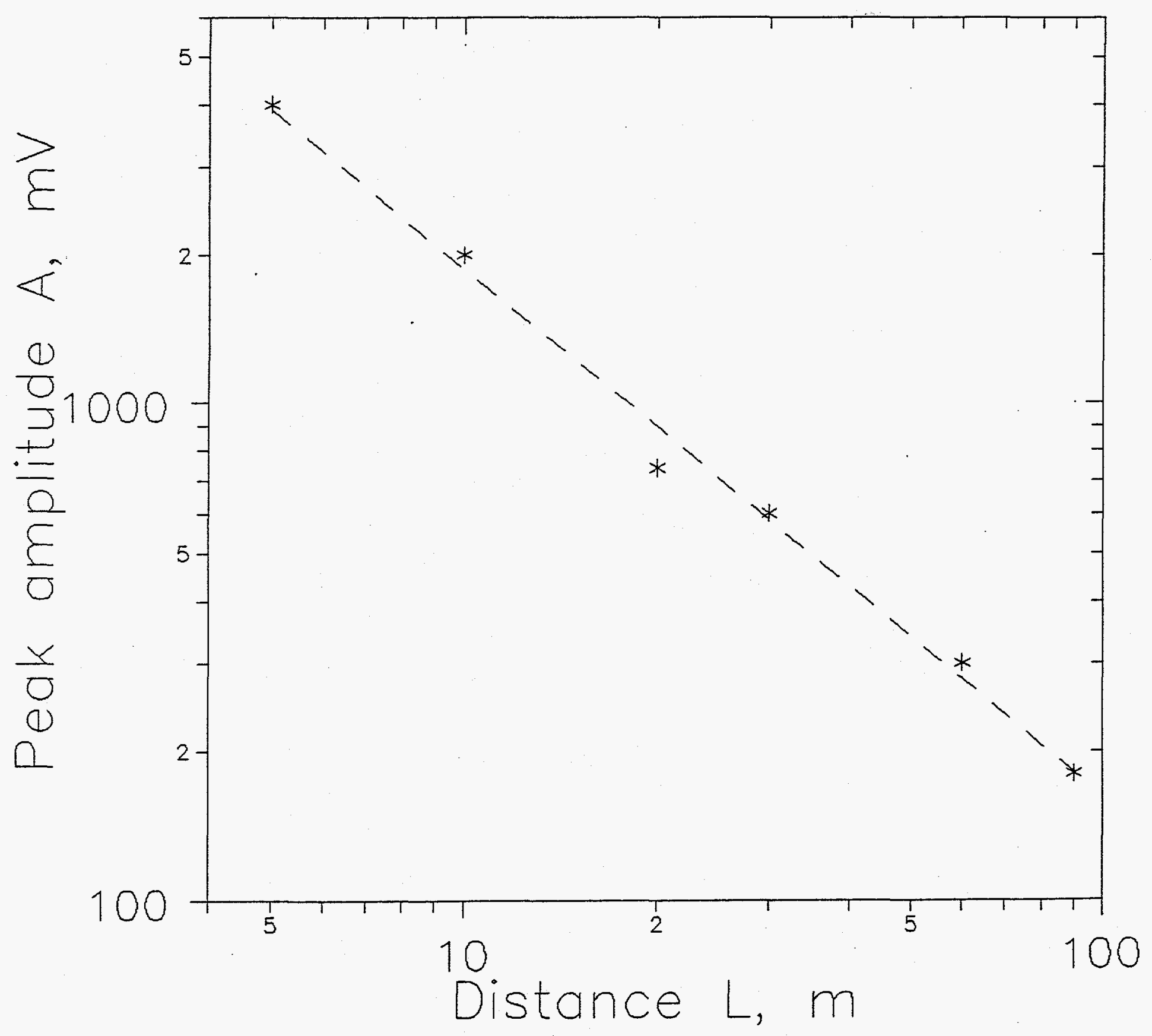


Fig 10

a)

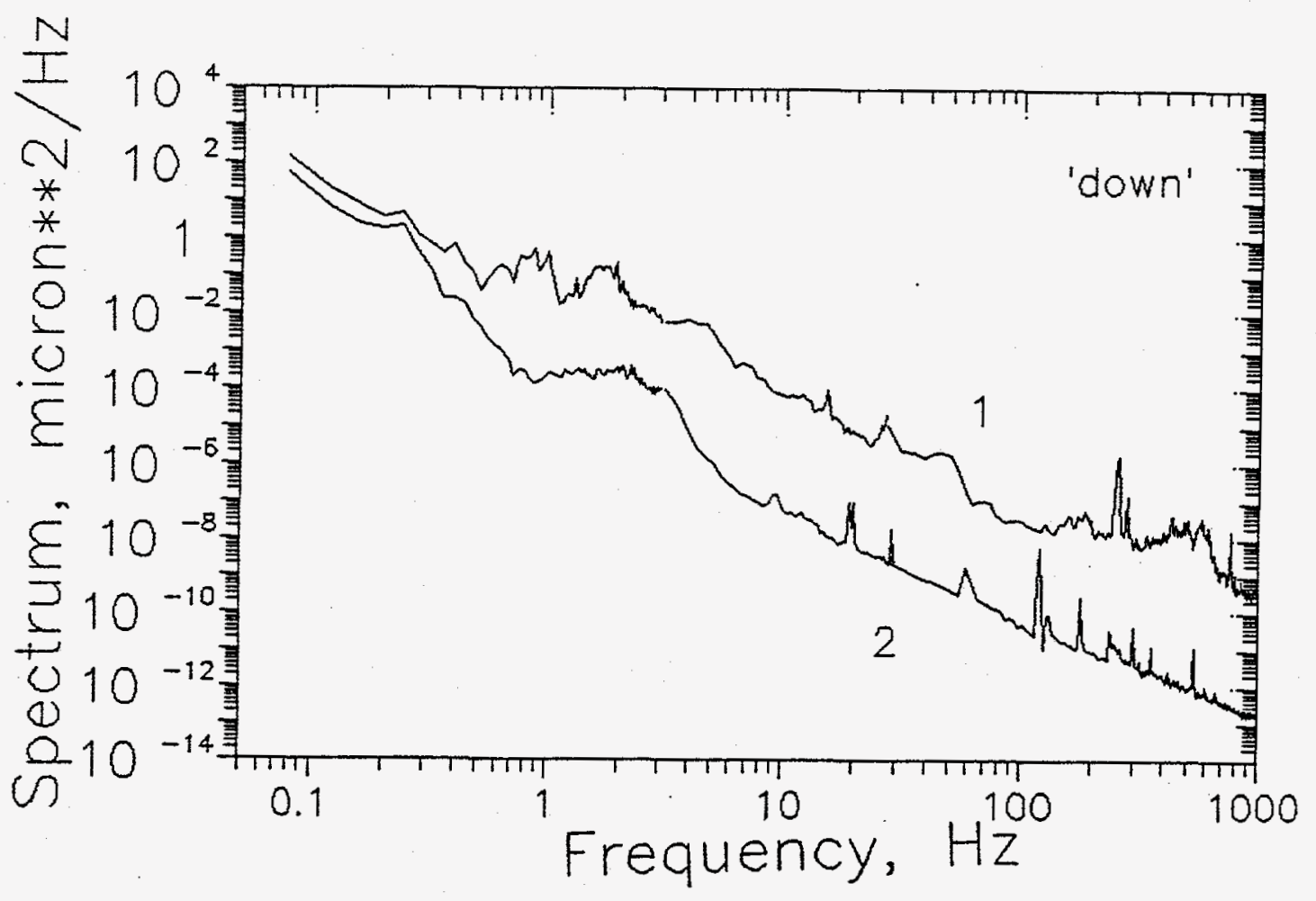


Fig 10 b)

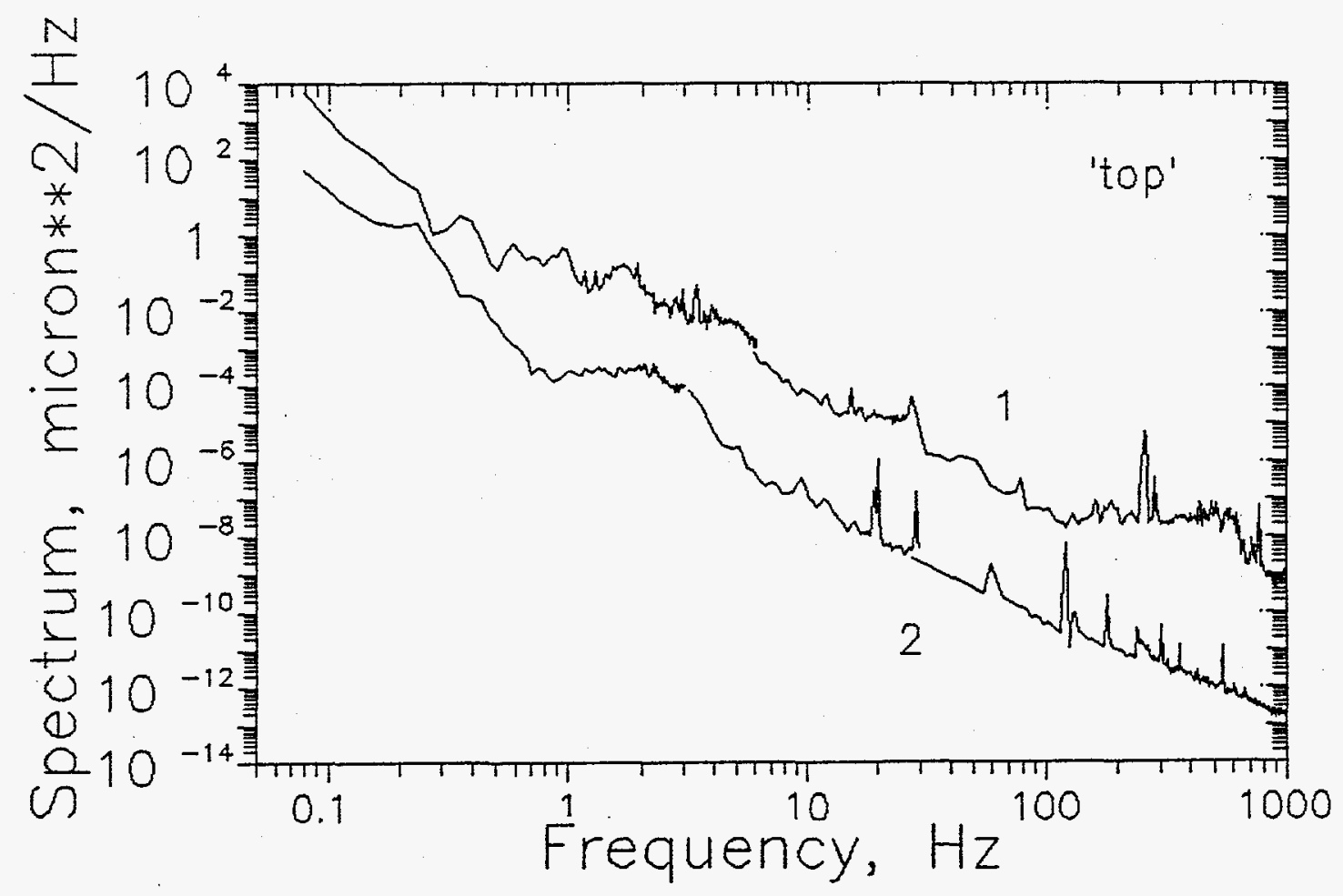




$$
\text { Fig } 11 \text { a) }
$$
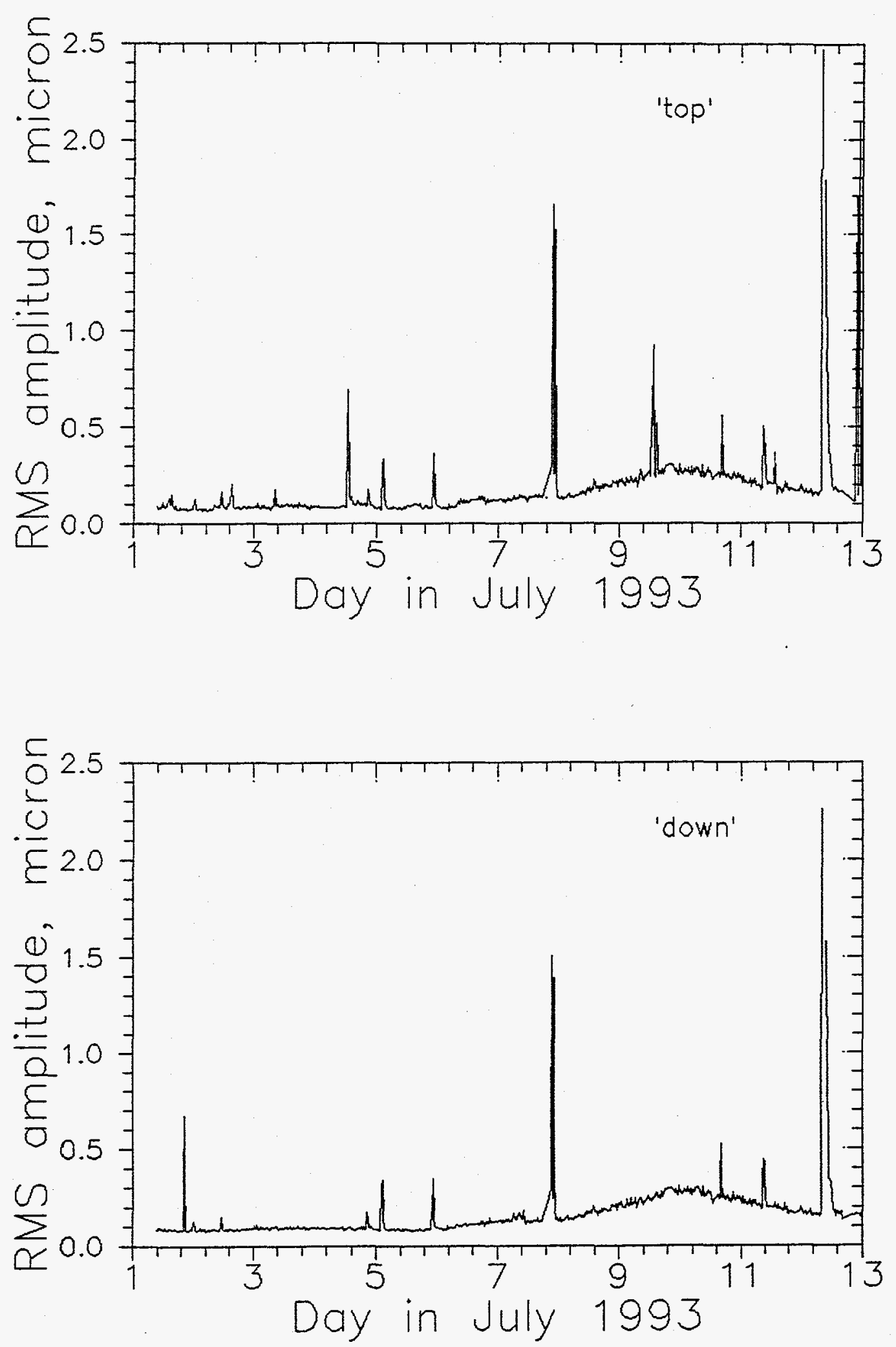
Fig 11 b)
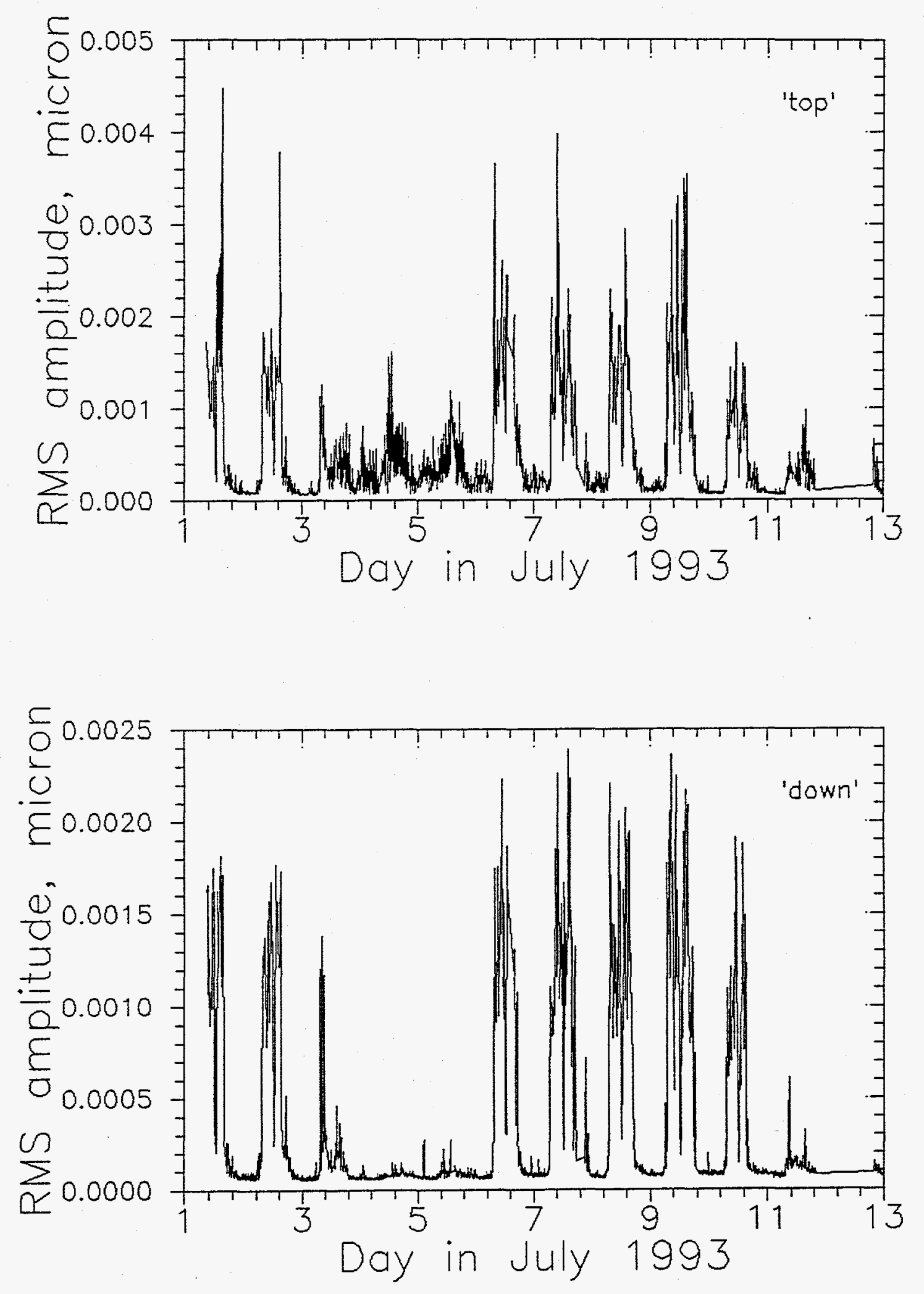
Fig 11 c)
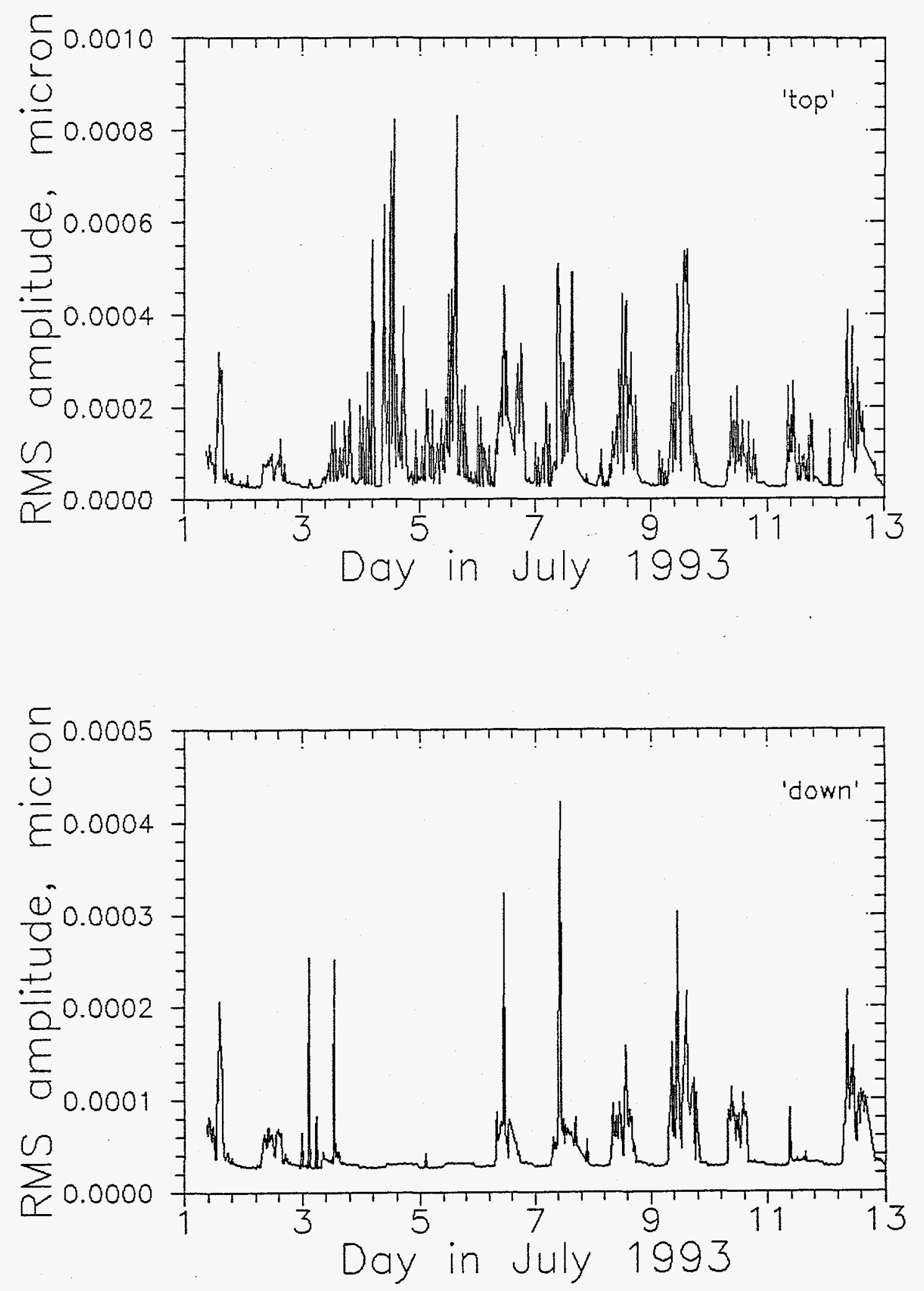

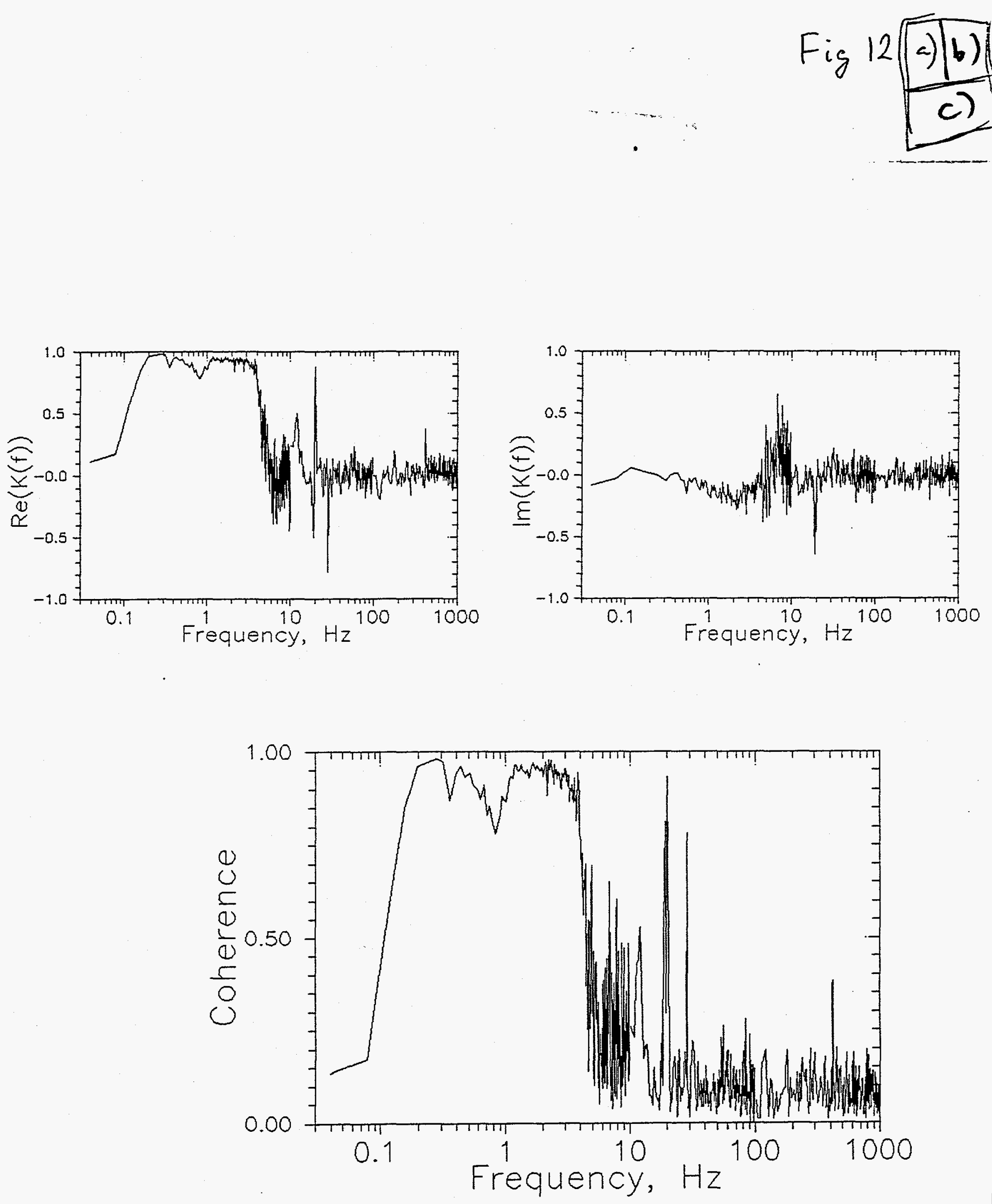
Fig 12d)

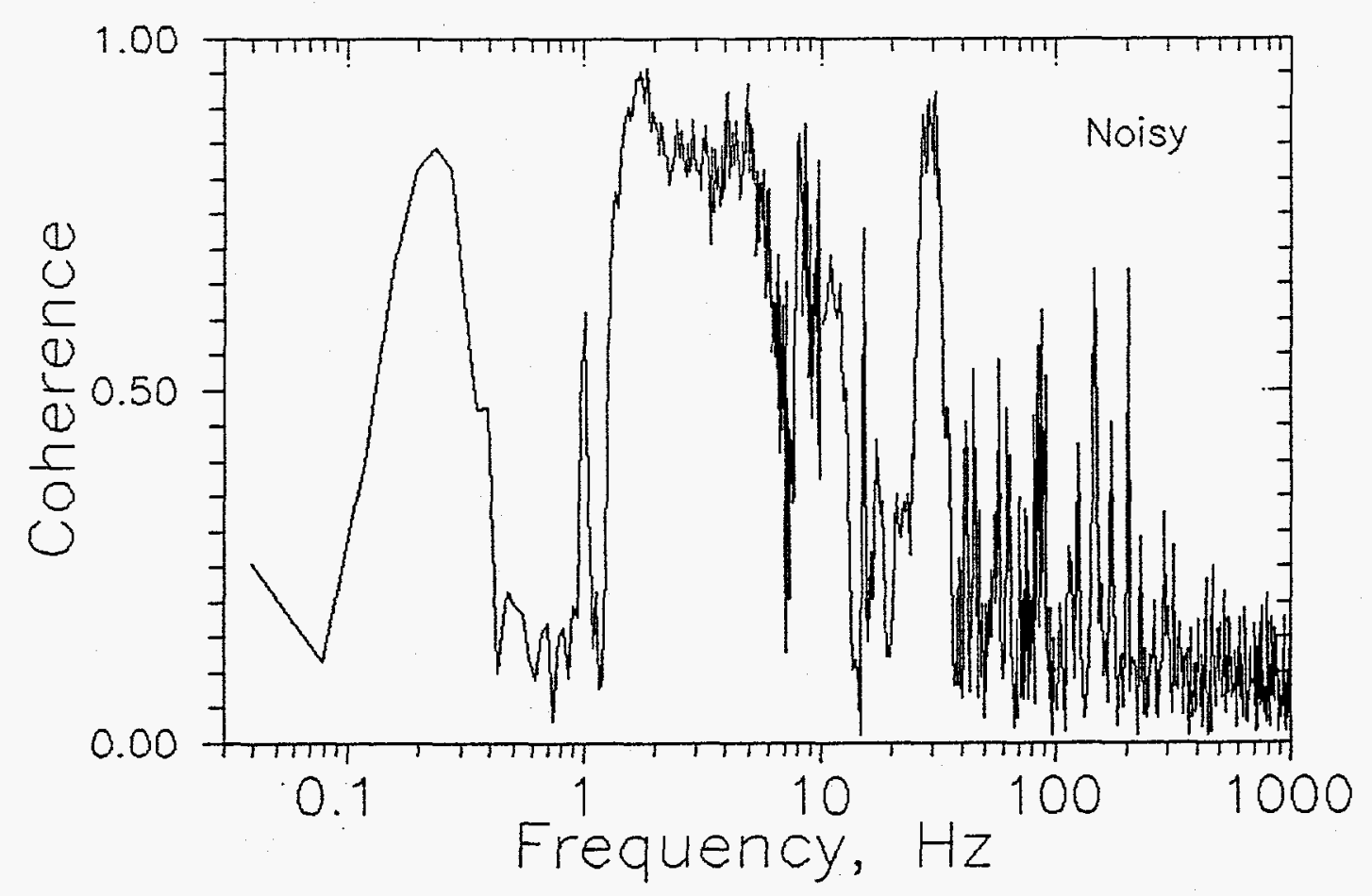


Fig 13 as

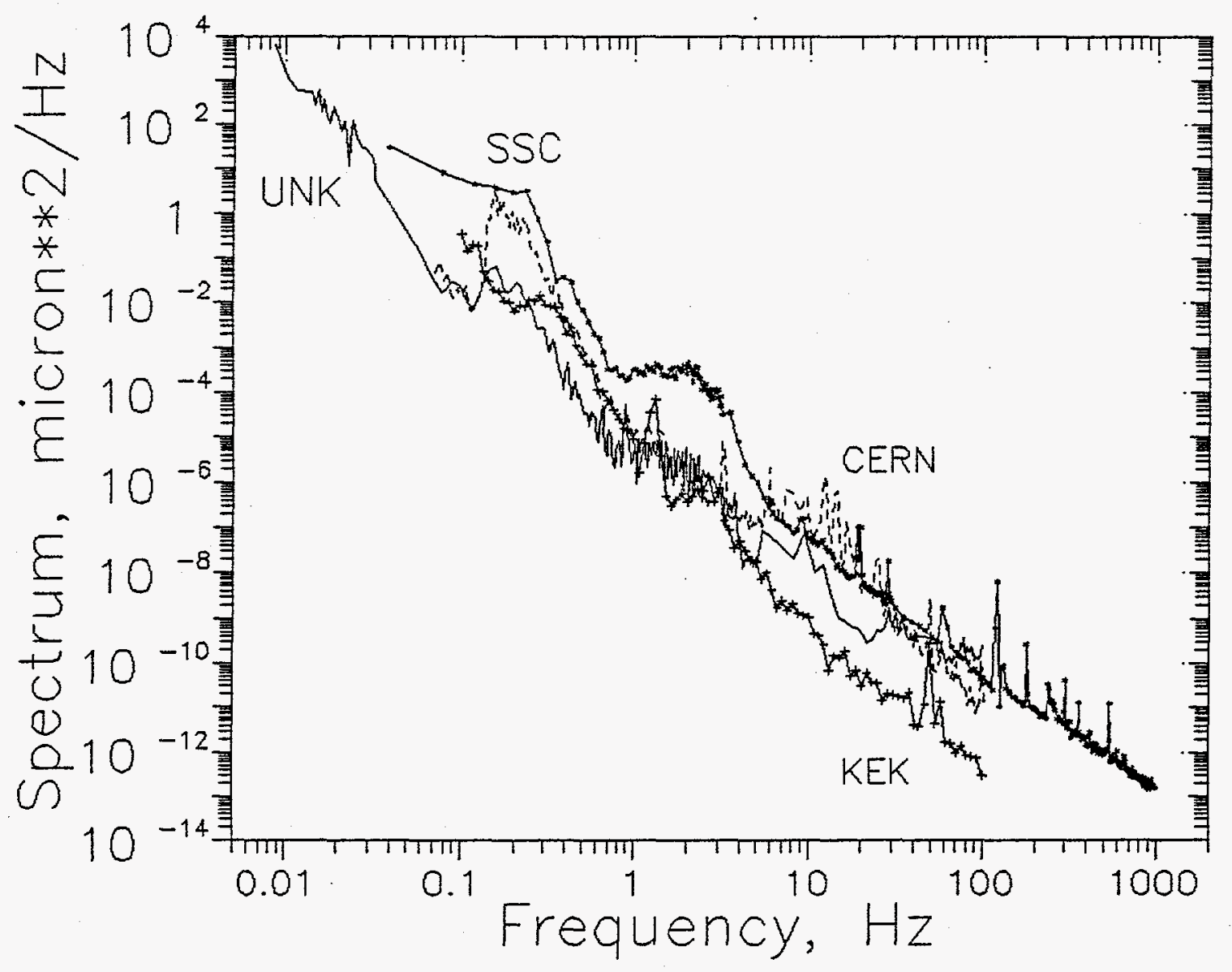




\section{DISCLAIMER}

This report was prepared as an account of work sponsored by an agency of the United States Government. Neither the United States Government nor any agency thereof, nor any of their employees, makes any warranty, express or implied, or assumes any legal liability or responsibility for the accuracy, completeness, or usefulness of any information, apparatus, product, or process disclosed, or represents that its use would not infringe privately owned rights. Reference herein to any specific commercial product, process, or service by trade name, trademark, manufacturer, or otherwise does not necessarily constitute or imply its endorsement, recommendation, or favoring by the United States Government or any agency thereof. The views and opinions of authors expressed herein do not necessarily state or reflect those of the United States Government or any agency thereof.

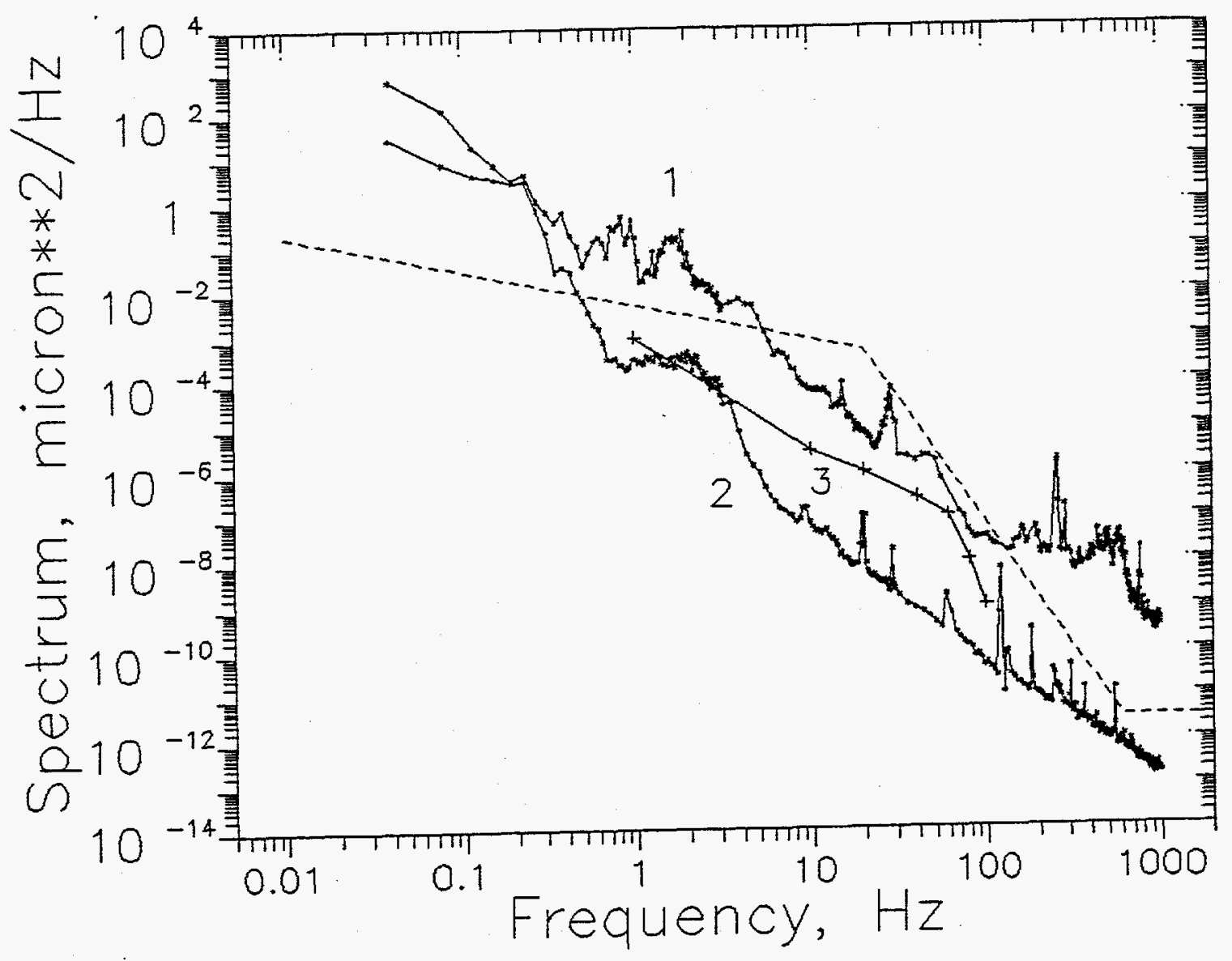

